\title{
ANALISIS PERSONAL BRANDING KOMIKA 'MONGOL STRES' DI TELEVISI TAHUN 2014-2018 (Penelitian Lanjutan)
}

\author{
Novrita Widiyastuti \\ LSPR Communication and Business Institute, novrita.w@1spr.edu
}

\begin{abstract}
Abstrak
Profesi yang perlu melakukan personal branding adalah komika, istilah untuk penampil pada acara stand-up comedy, agar dapat berbeda sehingga mereknya tidak mudah tenggelam di tengah banyaknya komika saat ini. Obyek penelitian ini adalah Mongol Stres, komika yang tampil di awal kepopuleran stand-up comedy di Indonesia tahun 2011 dan tetap tampil di televisi hingga tahun 2018. Penelitian ini merupakan penelitian lanjutan dari tesis berjudul "Analisis Personal Branding Komika Stand Up Comedy Show di Metro TV (Penelitian Mixed Methods Pada Komika Mongol)" oleh Novrita Widiyastuti pada tahun 2013. Hasil dari tesis ini: Mongol adalah komika yang memiliki persona yang kuat, masuk dalam pendongeng yang observasionalis, yaitu bercerita berdasarkan pengamatan yang ia lakukan sehari-hari. Tujuan dari penelitian: melihat konsistensi dari personal branding yang telah dilakukan oleh Mongol Stres, sesuai dengan kriteria personal branding yang efektif yaitu Spesialisasi dan Konsistensi (Rampersad). Dimensi ini diukur dengan konsep karakteristik yang membentuk persona komika yaitu Materi dan Delivery (Neal), ditambah delivery yaitu Kostum, Alat Bantu, Suara dan Penampilan Fisik (Helitzer \& Shatz). Strategi penelitian: analisis isi, metode pengumpulan data: observasi terhadap video Mongol yang melakukan stand-up comedy di televisi nasional dari tahun 2014 hingga 2018 dan dokumentasi dari berbagai sumber.
\end{abstract}

Kata Kunci : Penjenamaan Pribadi, Komedi Tunggal, Komika, Mongol, Komunikasi Pemasaran

\begin{abstract}
Profession who needs personal branding is comic (performer on stand-up comedy show) so his/her name would not be drowned in the midst of other comics. Research's object is Mongol Stres, one of the comic who performed in the early of popularity of stand-up comedy in Indonesia on 2011, and remain perform in television up to 2018. The research is a continuation of previous research for thesis with title "Personal Branding Analysis of Comic at Stand Up Comedy Show Metro TV (Mixed Methods Research On Comic Mongol)" by Novrita Widiyastuti on 2013. Result of the thesis: Mongol is a comic who has a strong persona, an observasionalist storyteller, who tell the stories based on his daily observations. Research objective: find out the consistency of the branding has been doing by Mongol Stres, as Rampersad's effective criteria of personal branding, which are: Specialization and Consistency. The dimension is measured by Neal's characteristic concept which shapes comic's persona: Material and Delivery, including Helitzer \& Shatz's criteria: Costume, Props, Voice and Physical Appearance. Research strategy: content analysis, data collecting: observation to videos of Mongol when he does Stand Up Comedy in television (2014 to 2018) and documentation from several sources.
\end{abstract}

Keywords: Personal Branding, Stand Up Comedy, Comic, Mongol, Marketing Communications

SSN: 2355-0287, E-ISSN: 2549-3299

http://ejournal.bsi.ac.id/ejurnal/index.php/jika 


\section{PENDAHULUAN}

Perkembangan stand-up comedy di Indonesia sejak dipopulerkan oleh 2 televisi swasta pada tahun 2011, saat ini mengalami pertumbuhan yang cukup pesat. Walaupun belum ada jumlah yang pasti berapa banyak komika yang secara professional terjun ke bidang ini, namun dilihat dari banyaknya komunitas Stand Up Indo (nama komunitas komika resmi di Indonesia) di 41 kota seluruh Indonesia, dari Medan hingga Jayapura, tentunya sudah banyak lahir talenta-talenta seni komedi tunggal di negeri ini. Tercatat sudah 5 televisi swasta yang menayangkan acara stand-up comedy di Indonesia dengan berbagai macam format: (1) Kompas TV "Stand Up Comedy Indonesia (SUCI)"; (2) Metro TV - "Stand Up Comedy Show"; (3) Indosiar - "Stand Up Comedy Academy (SUCA)"; (4) MNC TV - "Komika Vaganza", 5) RCTI - "Stand Up Everywhere" (Sastra, 2015). Pengelola stasiun televisi dituntut untuk memiliki kreativitas yang tinggi menghasilkan berbagai macam program penyiaran yang menarik, salah satunya adalah program Stand Up Comedy (Jaka Atmaja, 2019)

Stand-up comedy di Indonesia sebenarnya bukan dimulai dari kelima televisi tersebut, namun istilah ini mulai diperkenalkan oleh Ramon Papana dan rekannya, Harry de Fretes saat mereka menyelenggarakan lomba Lawak Tunggal di café milik mereka yaitu Boim Café di tahun 1992. Namun hingga tahun 2011 nama stand-up comedy tetap belum dikenal dan peminatnya belum terlihat. Hingga di awal tahun 2011, Ramon Papana memindahkan kafenya ke daerah Kemang, Jakarta Selatan dengan nama Comedy Café. Sejarah mencatat pada tgl 13 Juli 2011, beberapa calon komika (pada saat itu) hadir untuk tampil di kafe ini, seperti Raditya Dika, Pandji Pragiwaksono, Ernest Prakasa, Ryan Adriandhy, Asep Suadji, Isman H Suryaman, Arief Didu dll, yang akhirnya menjadi generasi awal komika yang tampil di televisi dan turut mempopulerkan stand-up comedy di kalangan anak muda (Papana, 2012, pp. 9-12). Hingga tulisan ini dibuat, komika generasi awal ini masih tetap bertahan sebagai komika profesional, yaitu yang sudah mendapatkan penghasilan dari stand-up comedy, walaupun beberapa di antaranya juga sudah menjajaki profesi lain seperti pemain film, sutradara, penulis dan lain-lain.

Mengekor kesuksesan senior-seniornya, maka para calon komika maupun komika yang baru terjun ke stand-up comedy berbondongbondong mencoba kemampuannya untuk melucu. Bahkan menurut Pandji Pragiwaksono, banyak yang baru 1-2 kali open mic (istilah untuk mencoba kemampuan stand-up comedy dan materi di depan umum), bahkan tidak sampai 'pecah' (istilah banyak penonton yang terbahak-bahak) namun sudah klaim bahwa mereka adalah komika. Segala macam teknik/cara dilakukan oleh para komika ini, dari yang orisinil kreasi sendiri hingga meniru komika yang sudah sukses, baik dari sisi materi, delivery maupun penampilan. Ada pula yang tampil biasa-biasa saja tanpa ada keunikan, datar, tidak menonjol sehingga setelah ia tampil, tidak ada yang bisa diingat oleh penonton darinya. Sama seperti cetakan kue yang bentuk kuenya sama satu dengan lainnya (cookies cutter).

Ditambahkan oleh Ernest Prakasa dalam video Youtube di akun Raditya Dika yang berjudul "Kumpul Founder Stand Up Comedy Indonesia! Malah ribut!" (diunggah 27 Februari 2019) akan banyaknya komika saat ini. Ernest Prakasa mengangkat fenomena SUC yang yang berada di persimpangan jalan, nasibnya tanda tanya. Komika Indonesia sedang mengalami masa transisi dan berat, terjadi over supply komika, namun tidak bisa diserap, sehingga komika banyak kekurangan undangan untuk tampil.

Hal ini sudah diprediksi sejak tahun 2013 oleh Novrita Widiyastuti dalam tesisnya yang menyoroti pentingnya personal branding bagi komika: "Bila hal ini terus dibiarkan, maka kualitas (baik materi maupun penampilan) dari para calon komika ini bisa jadi menjadi sama dan seragam, bukan beragam, karena jalan termudah dan tercepat adalah mengekor atau meniru komika yang sudah sukses. Padahal, komika yang hebat dan akan sukses adalah yang bisa menjaga orisinalitas dirinya. Industri hiburan yang menghasilkan 
produk yang sama secara terus-menerus bisa mengakibatkan kejenuhan dari pasar. Apalagi di industri pertelevisian yang budayanya cenderung pop, atau cepat naik tetapi cepat juga turun karena pasar yang cepat jenuh. Bila pasar sudah jenuh dan tidak ada pembaruan, maka industri ini lambat-laun bisa segera mati seperti industri hiburan lain." (Widiyastuti, 2013).

Di dalam dunia stand-up comedy, biasanya dikenal istilah persona untuk membedakan seorang komika dengan komika lainnya di depan penonton. Persona yaitu topeng yang penampil tampilkan kepada khalayak; semakin dekat persona tersebut dengan pribadi yang sesungguhnya, akan lebih mudah untuk dipertahankan (Boles, 2010). Tidak cukup hanya persona, komika juga seharusnya memiliki personal branding untuk bisa lebih 'menjual' kemampuan dan keahlian dirinya. Branding to personal berlaku sama, yaitu bagaimana mengkomunikasikan nilai-nilai, kepribadian atau ide-ide mengenai keahlian kita kepada khalayak untuk mendapatkan respons. Hal ini juga akan berimplikasi pada janji dan penciptaan kepercayaan khalayak kepada kita (Montoya \& Vandehey, 2002, hal. 15). Personal branding akan terbentuk dari persepsi publik yang dibangun secara bertahap (Fadeli, 2014). Berbagai manfaat akan didapatkan oleh seorang komika jika ia memiliki merek pribadi yang kuat dan hebat, yaitu: Menjadi orang nomor satu atau urutan teratas yang diingat orang lain apabila ada kesempatan atau proyek; Meningkatkan kepercayaan orang lain kepada kita; Meningkatkan prestise atau gengsi; Mampu menciptakan 'aura' yang dapat menarik orang yang tepat; Memberikan nilai tambah akan apa yang kita jual; Mendapatkan pengakuan; Diasosiasikan dengan tren terkini, karena kita merupakan bagian dari hal-hal baru; Meningkatkan potensi pendapatan dan kompensasi (Montoya \& Vandehey, 2002, hal. 23).

Salah satu komika senior yang memiliki personal branding dan menjadi obyek penelitian ini yaitu komika yang bernama panggung Mongol Stres, yang bernama asli Ronny Immanuel. Ia tampil pertama kali di
Metro TV yaitu pada penayangan perdana Stand Up Comedy Show tgl 11 September 2011. Mongol Stres tampil bersama 2 komika lain yaitu Soleh Solihun dan Iwel Wel. Mongol dipilih menjadi obyek penelitian ini adalah karena dari awal kemunculan stand-up comedy di TV hingga 2018 ia tetap eksis tampil sebagai komika, baik di televisi maupun acara off-air. Ia juga disebut-sebut pernah menjadi komika termahal, jadwal manggung-nya padat hingga seringkali 'bentrok'. Selain itu, ia memiliki merek pribadi / personal brand yang kuat, sesuai dengan hasil penelitian yang dilakukan oleh Novrita Widiyastuti (2013). Hasil penelitian tersebut, personal branding Mongol adalah komika yang observasionalis atau pengamat, karena ia mengamati dan menceritakan kembali hal yang ia amati. Karena itu pula, ia termasuk ke dalam The Storyteller atau pendongeng yaitu membagi pengalaman pribadinya namun didramatisasi. (Widiyastuti, 2013).

\section{KAJIAN LITERATUR Personal Branding}

Menurut Keller (2008, hal. 3), sebuah produk adalah segala sesuatu yang bisa kita tawarkan kepada pasar untuk mendapat perhatian, diakuisisi, digunakan atau dikonsumsi sehingga bisa memenuhi kebutuhan atau keinginan. Sebuah produk bisa berupa barang fisik seperti sereal, raket tenis atau mobil, bisa berupa orang atau manusia seperti figur politikus, entertainer atau atlet profesional. Menurut Gad \& Rosencreutz (2002, hal. 176), merek tidak hanya berbentuk perusahaan, barang ataupun jasa, merek juga bisa untuk individu atau manusia. Nama, penampilan, gaya berpakaian dan tingkah-laku adalah halhal yang membentuk identitas seseorang. Tanpa identitas, sebuah merek tidak akan memiliki persona di publik, karena identitas sebuah merek adalah wajahnya di publik (Drewniany \& Jewler, 2008). Bahkan menurut Thomas Gad (2002, hal. 20), manusia cenderung menjadi seperti lebih dan lebih seperti merek, dan merek menjadi lebih dan lebih menjadi seperti manusia. Sehingga produk bisa dianalogikan seperti manusia dan 
begitu juga sebaliknya, manusia juga bisa dianalogikan seperti produk.

Menurut Rajesh Setty (Rampersad, 2009, hal. 4), semua orang memiliki merek pribadi, karena secara sederhana semua orang membuat janji kepada dunia—sebagian ada yang secara eksplisit tetapi sebagian besar adalah implisit. Hanya saja, hampir semua orang tidak menyadari dan tidak mengelola merek yang dimilikinya secara strategik, konsisten dan efektif, bahkan tidak menyadari merek yang ada pada dirinya (Rampersad, 2009, hal. 12)

Banyak orang yang mereknya terbangun secara tidak disengaja. Namun personal branding yang sukses tidak terjadi secara tidak sengaja, karena personal branding adalah mengenai bagaimana kita mengendalikan proses mempengaruhi orang lain saat mereka mempersepsikan diri kita dan mengatur proses ini secara strategik dalam rangka mencapai tujuan besar kita (Montoya \& Vandehey, 2002, hal. 7). Secara sederhana, personal branding adalah proses mengkomunikasikan nilai-nilai unik dari seseorang kepada khalayak sasarannya agar terbentuk persepsi khalayak seperti yang ia harapkan.

Kriteria untuk keaslian personal branding yang efektif menurut Rampersad (2009, hal. 17-18): (1) Autentisitas/keaslian: menjadi merek kita sendiri. Merek kita harus bisa dibangun dari kepribadian yang sejati. Merek kita harus merefleksikan karakter, perilaku, nilai dan visi kita; (2) Integritas: kita harus mengikuti moral dan kode etik dengan yang sesuai dengan ambisi pribadi kita; (3) Konsistensi: kita sebaiknya tetap konsisten dengan perilaku kita; (4) Spesialisasi: fokus pada satu wilayah spesialisasi; (5) Otoritas: dipandang sebagai ahli pada bidang tertentu; (6) Istimewa/berbeda: bedakan diri kita sendiri berdasarkan merek kita. Hal ini butuh diekspresikan dengan cara yang unik dan berbeda dari pesaing dan membutuhkan nilai tambah bagi yang lainnya; (7) Relevan: apa yang kita yakini sebaiknya terhubung dengan apa yang khalayak sasaran anggap sebagai sesuatu yang penting; (8) Terlihat: harus sering disiarkan terus-menerus, kontinyu, konsisten dan berulang-ulang, hingga tertanam di benak khalayak; (9) Gigih: Merek kita membutuhkan waktu untuk tumbuh. Merek kita harus dibangun secara organik; (10) Perbuatan baik: diri kita harus diasosiasikan dengan nilai yang terkenal positif dan terpercaya; (11) Penampilan: Jika kita tidak tampil, dan meningkatkan kemampuan diri kita secara kontinyu, maka personal branding kita menjadi palsu.

\section{Stand-Up Comedy}

Stand-up comedy adalah sebuah dialog, antara komika dengan khalayaknya. Elemen yang terdapat pada stand-up comedy (Neal, 2008, hal. 23): (1) Elemen pertama yaitu materi. Komika harus memiliki sesuatu untuk disampaikan; (2) Elemen kedua yaitu penyampaian atau delivery. Bukan sekedar apa yang kita sampaikan, tetapi bagaimana kita menyampaikannya; (3) Elemen ketiga yaitu khalayak. Mereka ada disana, dan siap untuk tertawa.

Ada 7 (tujuh) tipe dasar kepribadian komedian stand-up menurut Shore (2004, hal. 38-42): (1) Sarkastik: ekspresi pahit, mengomentari sebuah hal, mengejek, mencemooh, menggunakan bahasa ironi atau satir; (2) Egosentris / didorong Ego: ke-aku-an atau diri sebagai pembeda diri dengan orang lain, memiliki atau menautkan diri sebagai pusat dari segala hal yang berhubungan dengan dunia; (3) Korban: seseorang yang dihancurkan, dikorbankan atau dilukai oleh orang lain dengan beberapa kondisi atau agen; orang yang dicuri atau ditipu; (4) Orang yang sial/sindrom "kasihani-aku": seseorang yang mendapatkan hal yang terburuk dari perjuangannya, korban dari ketidakadilan; (5) Pemalu / pendiam: hati-hati atau diam saat melakukan sesuatu; seseorang yang sulit untuk menghadapi kesadaran diri dan membangun hubungan pribadi dengan orang lain. Pendiam: disiplin untuk tidak menunjukkan emosi atau mengekspresikan opini atau untuk terbuka saat kontak intim dengan orang lain; (6) Keras kepala: seseorang yang berekspresi dengan menghakimi atau meyakini sesuatu yang lebih kuat dari anggapan tetapi tidak bukan hal 
yang positif; (7) Observasionalis/pengamat: Seseorang yang memberi komentar atau penilaian berdasarkan apa yang telah mereka amati selama ini; seseorang yang mengamati, yang melihat tanpa berpartisipasi secara aktif; seseorang yang hadir atau memperhatikan tanpa ikut serta; seseorang yang mempersepsikan, mengomentari, dan/atau memberikan pendapat.

Stand-up Comedy (SUC) adalah penampilan langsung dimana komedian menyampaikan lelucon dan atau berperilaku dengan cara yang didesain untuk memanen tawa, terkadang menggelikan, yang diarahkan oleh persona komika tersebut atau oleh persona komika lain. Topik yang diangkat bisa isu sosial atau topik lain yang tidak asing bagi khalayaknya. Peran yang paling penting bagi komedian SUC adalah untuk mengorkestra indera homogenitas, komunitas dan berbagi nilai dan perspektif (Charney, 2005, hal. 575): (1) Biasanya, komika stand up mempresentasikan persona yang konsisten untuk merepresentasikan perspektifnya dari hasil observasi yang mereka lakukan. Tetapi beberapa pemain drama postmodern menciptakan karakter yang dramatis sebagai koleksi dari teks yang terpecah dibandingkan dengan individu yang secara psikologis konsisten, beberapa komika juga menghindari mempresentasikan persona yang nyata (Connor, 2004, hal. 108). Seorang komika bisa mendapatkan tawa walaupun dengan kesalahan-karena karakter adalah bagian dari lelucon itu sendiri (Helitzer \& Shatz, 2005, hal. 223). Ditambahkan Helitzer \& Shatz, karakteristik bisa ditingkatkan atau dicapai menggunakan kombinasi dari (2005, hal. 240): Kostum, adalah hal yang pertama diperhatikan oleh khalayak; (2) Alat bantu (Props), seperti cerutu, hidung, kumis dan kacamata adalah alat bantu/props yang biasanya digunakan sebagai simbol komedi; (3) Suara, biasanya adalah instrumen fisik yang paling jelas terlihat untuk menyampaikan karakter; (4) Penampilan fisik, penampil harus bisa jujur dan nyaman dengan karakter yang dipilihnya. Tata rias dan lampu bisa mengubah penampilan. Props dan kostum bisa memperkuat karakter. Tetapi ada beberapa hal yang hampir tidak mungkin diubah: usia, warna kulit, tinggi badan dan jender. Untuk jangka panjang, kepribadian harus berdampingan dengan karakternya. Menurut Helitzer \& Shatz (2005, hal. 228237), ada 7 karakter umum pada stand up dan sketsa komedi: (1) The Jester / pelawak: materi dari pelawak ini adalah serangkaian one-liners dan komentar singkat pada adegan kontemporer. Pelawak yang sukses adalah yang memadukan penyampaian, isi/konten dan sikap ke karakter mereka; (2) The Sad Sack / Pemalu: komika memainkan tokoh yang tidak aman, selalu mencari persetujuan, dibuat bingung oleh lawan jenisnya, sulit untuk mendapatkan kencan atau menjalin hubungan kerja; (3) The Drug Rebel / Pemabuk: Daya tarik dari badut alkoholik berubah menjadi daya tarik dengan pemabuk; (4) The Intellectual / Intelektual: Woody Allen adalah maskot dari intelektual komika selama 20 tahun. Humornya berdasarkan keganjilan antara penampilannya dengan materi yang disampaikannya; (5) The Political Satirist / Satir Politik: Satir merefleksikan siapa dan apa yang ada di berita yang sedang hangat saat itu. Satir menyerang sasaran sosial dan politik, sehingga beresiko jika khalayaknya besar dan beragam; (6) The Storyteller / Pendongeng: Mereka membagi pengalaman pribadi mereka hanya didramatisasi dengan hati-hati. Materinya cenderung untuk menjauhi berita terhangat dan konsentrasi pada hal yang lebih tahan lama, seperti keluarga, bisnis dan situasi sosial, (7) The Rube / Orang Udik: tipe ini akan lebih mengena pada khalayak di pedesaan, dan membuat mereka merasa lebih superior dibanding komikanya.

\section{METODE PENELITIAN}

Penelitian ini adalah penelitian lanjutan dari penelitian sebelumnya yaitu tesis dari penulis sebagai syarat kelulusan program magister. Penelitian ini akan tetap menggunakan paradigma penelitian konstruksionis, yang memandang realitas kehidupan sosial dari hasil konstruksi bukanlah realitas yang natural. Oleh karena itu, konsentrasi analisis dari paradigma ini adalah bagaimana 
menemukan realitas atau peristiwa tersebut dikonstruksi dan dengan cara apa konstruksi itu dibentuk (Eriyanto, 2008). Sehingga penelitian ini menyajikan interpretasi dari konstruksi personal branding yang dibangun oleh obyek penelitian, baik disengaja maupun tidak disengaja dilakukan olehnya. Penelitian ini berusaha untuk obyektif dan menangkap realitas yang telah dikonstruksi di dalam sebuah teks.

Pendekatan penelitian yang digunakan adalah pendekatan kuantitatif. Jenis penelitian yang akan digunakan adalah deskriptif dengan mengadakan klasifikasi dan penilaian standar norma. Penelitian ini bertujuan ingin meneliti fenomena yang terjadi di masa saat penelitian ini dilakukan. Strategi penelitian ini adalah analisis isi untuk memetakan dan menggambarkan teks yang disampaikan dan dilakukan oleh Mongol yang membentuk personal branding-nya.

Penelitian akan dilakukan dengan menganalisis video-video saat Mongol Stres tampil sebagai komika di televisi nasional yang didokumentasikan di youtube.com. Penelitian dimulai di bulan Januari 2020 dan berakhir di bulan Juni 2020. Saat melaksanakan penelitian, peneliti akan melakukan analisis isi kuantitatif berdasarkan panduan penelitian berikut ini:

Tabel 1. Panduan Penelitian Analisis isi Kuantitatif

\begin{tabular}{cll}
\hline Dimensi & Sub Dimensi & Indikator \\
\hline Spesialisasi & 1. Materi & Materi dan \\
& 2. Delivery: & Delivery \\
& Kostum, Suara, & yang sering \\
& Alat Bantu, & diangkat \\
& Penampilan & dan \\
& seberapa \\
& Fisik & banyak \\
\hline Konsistensi & 1. Materi & Materi dan \\
& 2. Delivery: & Deliveri \\
& Kostum, Suara, & yang selalu \\
& Alat Bantu, & secara \\
& Penampilan & konsisten \\
& Fisik & diangkat \\
\hline
\end{tabular}

Sumber: Laporan Akhir Penelitian

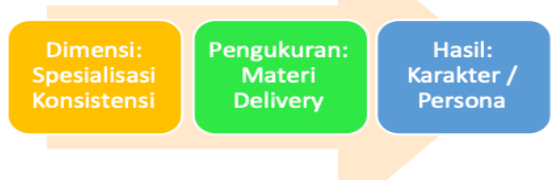

Sumber: Laporan Hasil Penelitian

Gambar 1. Kerangka Berpikir

Kotak pertama adalah kriteria personal branding yang efektif menurut Rampersad. Dari 11 kriteria, hanya 2 kriteria yang akan diteliti untuk penelitian karena disesuaikan dengan tujuan penelitian ini yaitu meneliti konsistensi personal branding dari obyek penelitian. Kriteria tersebut adalah: (1) Spesialisasi: untuk melihat seperti apa spesialisasi dan keunikan dari Mongol yang berbeda dengan komika lain pada saat ia di front region / wilayah depan yaitu melakukan stand-up comedy di televisi; (2) Konsistensi: untuk melihat hal-hal apa yang konsisten dikomunikasikan oleh Mongol pada saat ia melakukan stand-up comedy di televisi. Kotak adalah pengukuran untuk mengukur dua kriteria yang menjadi dimensi. Kotak ketiga adalah hasil personal branding. Pada penelitian sebelumnya, Mongol Stress sebagai obyek penelitian yang sama hasilnya adalah komika yang observasionalis atau pengamat, yaitu seseorang yang memberi komentar atau penilaian berdasarkan apa yang telah mereka amati selama ini (Shore, 2004), karena Mongol mengamati dan menceritakan kembali atas hal yang ia amati, seperti perilaku KW, copet, orang Manado dan lain-lain. Pada saat ia mengekspresikan apa yang ia amati, Mongol merupakan storyteller atau pendongeng, yaitu membagi pengalaman pribadi mereka hanya didramatisasi dengan hati-hati.

\section{PEMBAHASAN}

Gambaran umum Obyek Penelitian

Mongol Stres bernama asli Rony Immanuel, berasal dari keluarga sederhana di Manado. Ia merantau ke Jakarta, mencoba peruntungan dengan kerja serabutan dan berganti-ganti pekerjaan. Ia lalu tanpa sengaja mencoba 
stand-up comedy ketika ia diminta oleh teman-temannya untuk tampil di suatu Comedy Café. Penampilannya itu yang menjadi perdana karirnya di industri ini dan menjadikan Mongol sebagai salah satu (no.5) dari 7 stand-up comedy yang paling populer menurut lihat.co.id (Lihat.co.id, hal. 2012). Gayanya yang ceplas-ceplos setiap kali show sering membuat penonton tertawa, penguasaan tehnik delivery yang kuat serta play the room-nya yang baik membuat Mongol menjadi salah satu stand up komedian Indonesia teratas saat ini (Mongol dari Stand Up Comedy Bisa Beli Rumah, 2012).

Diakui Mongol, ia tidak pernah kehabisan materi lawakan, ia bisa menjadikan hal sekitarnya menjadi materi lawakan. Intinya, seorang komika harus jeli dengan lingkungan sekitar. Materi paling mudah adalah melecehkan diri sendiri yang membuat orang lain tertawa (Mongol Pernah Hidup Lontang Lantung dan Tidur di Emperan Toko, 2012). Secara fisik, ia bermata sipit, hidung pesek dan berkulit hitam. Jika berbicara, ia berlogat Batak. Ia sering diejek artis yang jelek, namun ejekan itu yang akhirnya dijadikan bahan lawakan olehnya dan memberikan keberuntungan hingga ia menjadi artis. Menurutnya, dibandingkan membicarakan kejelekan orang lain, lebih baik membicarakan dirinya sendiri atau kekurangan fisiknya, agar aman (Mongol dari Stand Up Comedy Bisa Beli Rumah, 2012). Banyak orang tertawa terbahak-bahak saat dia melawak seputar dirinya maupun realitas sosial di masyarakat, ditambah lagi dengan ekspresi wajahnya yang membuat orang tertawa. Materi lawakannya tidak jauhjauh seputar kaum homoseksual yang disebutnya dengan istilah $K \boldsymbol{W}$. Saat memulai debut sebagai seorang komika, ia mulai mengangkat soal kebangkitan kaum $K W$. Sejarah istilah $K W$, yaitu karena dahulu istilahnya adalah 'maho' namun buat dia maho agak rasis, apalagi kata 'homo', itu sebabnya dia menggunakan kata $K W$ karena terdengar lebih ringan. Misalnya, barang ada yang asli, ada yang $K W$. Begitu pula dengan laki-laki, ada yang orisinil ada yang sedikit dibawahnya atau $K W$ (Kurniawan, 2012).
Selain persoalan keseimbangan jadwal antara menjadi komika dan pelayan Tuhan, Mongol harus menghadapi kritik jemaat karena seringnya mengambil bahan lawakan tentang Gereja. Misalnya tentang jemaat yang tertidur saat khotbah atau yang terlalu khusuk hingga tak sadar dompetnya dicuri. Sebagian besar lawakan Mongol memang bermain di batas sensitivitas seperti itu. Mulai dari etnisitas hingga homoseksualitas. Oleh karena sering menggunakan istilah $K W$, pria yang masih sering betah melajang itu sampai digosipkan sebagai bagian dari komunitas tersebut, meskipun ditepisnya (Jpnn.com, 2011). Ia bahkan menyebut dirinya adalah pakar $\boldsymbol{K W}$ Indonesia, tetapi ia mengaku dirinya sendiri bukan $K W$ (Mongol dari Stand Up Comedy Bisa Beli Rumah, 2012).

Secara umum, persona dari Mongol (Widiyastuti, 2013) adalah sebagai berikut: (1) Delivery / Cara Penyampaian: ceplasceplos, berlogat Batak, bergaya seperti waria/melambai, menggunakan baju ketat \& kadang menggunakan motif bunga-bunga, berkacamata dan sering berganti-ganti kacamata, sering menaruh kacamata di atas kepala sambil berbicara, sering menggunakan istilah coy atau sob; (2) Materi yang diangkat: pakar KW Indonesia, menganggap dirinya adalah artis, melecehkan diri sendiri, mengangkat masalahnya yang sering diejek sebagai artis yang jelek, membicarakan diri sendiri atau kekurangan fisiknya, kaum homoseksual/KW, agamanya atau perilaku jemaat di Gereja, etnis (Batak dan Manado)

\section{Analisis Personal Branding}

Personal branding dan komunikasi Mongol dilakukan dengan cara mengamati 17 (tujuh belas) video stand-up comedy di televisi swasta nasional, antara lain: MNC TV, TV One, Indosiar, NET TV, Metro TV, JakTV, Trans7 yang diunduh dari situs youtube.com. Video-video tersebut merupakan potongan klip acara yang ditayangkan di TV swasta nasional tersebut yang menampilkan Mongol sebagai komika dan ditayangkan pada: (1) 9 Agustus 2015 - Metro TV; (2) 5 Oktober 2015 - Jak TV; (3) 6 November 2015 MNCTV; (4) 12 November 2015 - MNCTV; 
(5) 16 November 2015 - MNCTV; (6) 20 November 2015 - MNCTV; (7) 21 November 2015 - MNCTV; (8) 23 November 2015 MNCTV; (9) 3 Desember 2015 - MNCTV; (10) 10 Desember 2015 - MNCTV; (11) 14 Desember 2015 - MNCTV; (12) 15 Desember 2015 - MNCTV; (13) 23 Desember 2015 NET TV; (14) 25 Maret 2016 - Trans7; (15) 11 Mei 2016 - Trans7; (16) Agustus 2017 TV One; (17) 18 Oktober 2018 - Indosiar.

Analisis personal branding lanjutan Mongol pada tahun 2015 sampai dengan 2018 menggunakan pendekatan kuantitatif dilihat dari materi dan delivery-nya dengan dimensi Spesialisasi dan Konsistensi. Video Mongol yang sedang berada di televisi swasta hanya terekam hingga tahun 2018. Sisanya ia lebih banyak tampil off-air atau bukan di televisi. Untuk video off-air tidak ikut dianalisis karena tidak relevan dan kualitas video atau audionya kurang bagus.

\section{Spesialisasi}

Berdasarkan pengamatan dari 17 video terlihat bahwa Mongol banyak melontarkan materi yang kurang lebih masih sama dengan personanya di tahun 2013 yaitu mengenai selfdeprecating (mengolok-olok / menjelekkan diri sendiri), mengenai laki-laki $\mathrm{KW}$ atau tidak normal, dirinya yang orang Manado, merasa dirinya ganteng, sering dikira copet, menganggap dirinya artis atau sering dikira orang Batak karena bentuk wajahnya menyerupai orang Batak. Namun, dari tahun 2015 hingga 2018, ia mulai menambahkan materi-materi baru yang belum ada di personanya sebelumnya, yaitu: kelakuan (perilaku) orang Indonesia, bagaimana menghalau Hantu (Pocong, Wewe Gombel dan Kuntilanak), keanehan di lirik lagu anakanak, kelakuan (perilaku) perempuan serta ia mulai mengungkap alasan ia menaruh kacamata di kepala. Selain berkomedi, ia juga mulai mencoba menyelipkan pesan-pesan moral kepada penonton seperti: tidak boleh seks bebas, tidak boleh menggunakan narkoba dan lain-lain yang tetap dikemas dengan cara yang lucu.

Materi pertama yang terbanyak diangkat yaitu self-deprecating atau menghina diri sendiri atau mengejek wajahnya sendiri yang dianggap tidak ganteng bagi orang kebanyakan. Bahkan, materi mengolok-olok dirinya sendiri seringkali menjadi materi yang dominan dibawakan di hampir setiap kemunculannya. Tercatat materi ini dominan di 7 dari 17 video yang diamati. Hanya ada 2 kali kemunculannya yang tidak menjelekkan dirinya, yaitu video tgl 6 November 2015 dan 10 Desember 2015, karena pada video di tanggal tersebut, materi yang dominan adalah mengenai laki-laki $\mathrm{KW}$ atau tidak normal. Begitu pula pada video yang materinya tidak dominan self-deprecating, biasanya Mongol akan mengangkat materi seputar pengamatan atau observasi akan kejadian di sekelilingnya, sehingga ia tidak membicarakan mengenai dirinya. Pada penelitian sebelumnya (2013), self-deprecating ini menempati posisi ke-4 setelah materi KW, Menado dan Kristen.

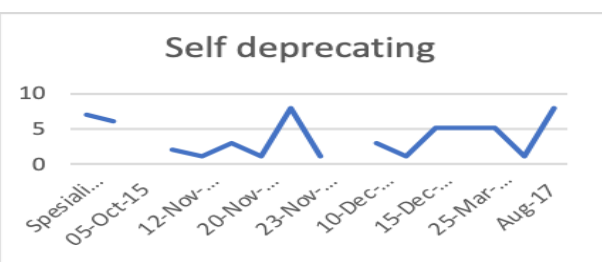

Sumber: Laporan Akhir Penelitian

Gambar 2. Spesialisasi Mongol Stres - selfdeprecating

Materi kedua yang pasti akan selalu ia angkat yaitu mengenai laki-laki yang berperilaku tidak seperti laki-laki pada umumnya, atau kemayu. Ia menyebut laki-laki tersebut sebagai KW (yang merupakan kependekan dari kwalitas, yaitu sebutan yang sering digunakan pada tas bermerek namun palsu), karena laki-laki yang sesuai standar umum adalah yang macho, kuat, gagah dan sebagainya. Sedangkan laki-laki yang ia ceritakan adalah yang ngondek, bersuara sengau, kadang tidak gagah sehingga ia anggap itu adalah laki-laki palsu. Ia banyak menceritakan ciri-ciri laki-laki KW ini yang ia dapatkan dari pengamatan. Karena banyaknya cerita yang ia kemukakan, sehingga ia sering dijuluki pakar KW, bahkan seringkali dianggap golongan yang sama. Biasanya ia juga sering menggunakan kata Homo, namun 
belakang ia jarang menggunakannya. Khusus untuk materi KW ini, hampir tidak ada materi baru jika dibandingkan dengan penelitian sebelumnya. Ia hanya mengubah ceritanya sedikit, tapi inti dari cerita ataupun ciri-ciri yang ia ceritakan kurang lebih intinya sama. Namun, karena ia menceritakannya dengan act-out atau dipraktekkan, sehingga tetap lucu bagi penontonnya. Ia juga sering mengajak penonton atau pembawa acara lain untuk menguji kadar $\mathrm{KW}$ mereka, yang mendulang tawa dari penonton dan pengisi acara lainnya.

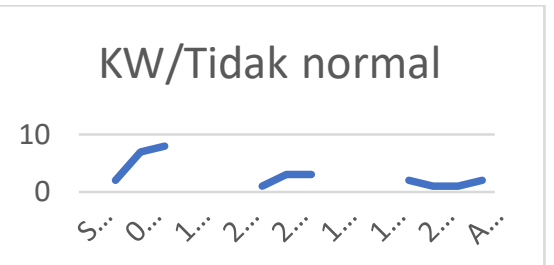

Sumber: Laporan Akhir Penelitian

Gambar 3. Spesialisasi Mongol Stres - KW

Materi ketiga yang banyak diangkat oleh Mongol dan belum ditampilkan sebelumnya yaitu adalah kelakuan (perilaku) orang Indonesia yang kadang kurang beretika, aneh dan lucu bagi Mongol. Perilaku yang dimaksud misalkan ketika datang ke acara pernikahan biasanya rebutan makanan, atau akal-akalan saat mengambil makanan. Atau perilaku lainnya ketika di toilet yang dikupas dari segala sisi. Walaupun materi yang diangkat tidak terlalu banyak, bahkan diulangulang dari episode satu ke episode lainnya, namun karena pembawaannya yang jenaka, sehingga mampu membuat penonton terbahak-bahak. Mungkin juga karena perilaku tersebut dekat dengan penonton atau sering mereka temui sehari-hari.

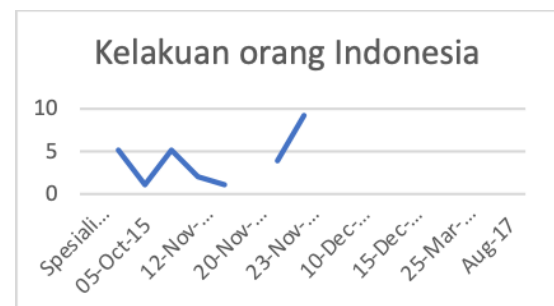

Sumber: Laporan Akhir Penelitian

Gambar 4. Spesialisasi Mongol Stres kelakuan orang Indonesia
Materi-materi lain yang sering diangkat di penelitian sebelumnya (2013) dan sesuai dengan persona Mongol yaitu: kenyataan ia keturunan Manado, atau juga kebiasaan orang Manado yang lucu; ia menganggap dirinya ganteng walaupun setelah itu ia kembali menghina dirinya atau juga memuji orang lain yang ganteng; seringkali dikira copet karena wajahnya yang menyeramkan; dan seringkali dikira orang Batak bahkan oleh orang Menado sendiri.

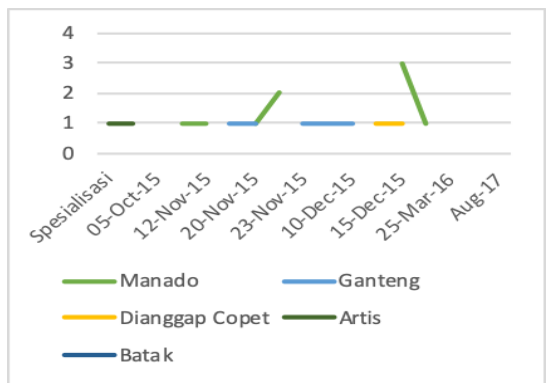

Sumber: Laporan Akhir Penelitian

Gambar 5. Spesialisasi Mongol Stres -

Manado, Ganteng, Dianggap copet, Artis, Batak

Pada penelitian sebelumnya, ia banyak mengangkat mengenai perilaku aneh penganut agama Kristen. Namun mungkin karena topik ini sedang sensitif, ia lebih banyak menceritakan mengenai tips mengusir hantu, topik horror sedang disukai anak muda.

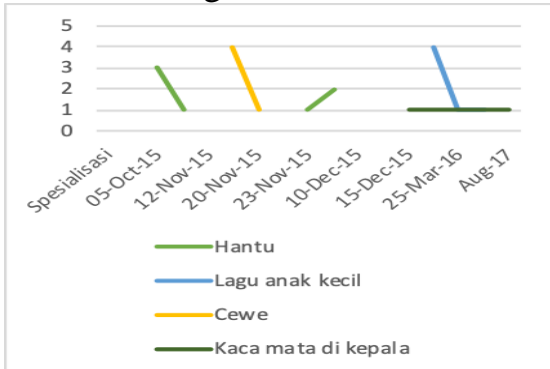

Sumber: Laporan Akhir Penelitian

Gambar 6. Spesialisasi Mongol Stres - Hantu, Lagu anak kecil, Cewe, Kaca mata

Ia juga akhirnya mengungkap misteri kenapa ia meletakkan kaca mata di kepala, bukan di wajah seperti lazimnya orang kebanyakan. Ia mengaku matanya tidak minus, tapi yang minus adalah otaknya (atau dianggap gila), sehingga harus dibantu kaca mata minus. 
Dari sisi delivery atau penyampaian materi yang dilakukan Mongol, dari sisi kostum, alat bantu, suara atau logat dan penampilan fisik hampir tidak ada perubahan yang berarti jika dibandingkan dengan penelitian sebelumnya (2013). Dari 17 video tersebut, kostum yang dikenakan Mongol bergaya sama, yaitu semiformal, seperti: menggunakan kaus / t-shirt atau kadangkala kemeja, beberapa kali dipadu dengan rompi, jaket atau blazer, celana jeans, anting berlian di telinga kiri, kacamata dan kalung. Pada penelitian sebelumnya, ia menggunakan cincin di jari manis, namun kini ia menggunakan cincin di jari kelingking yang kadang berpindah dari kelingking kiri ke kelingking kanan. Ia seringkali menggunakan kaus ketat seperti KW yang menjadi materi andalannya.

Alat bantu yang dibawa Mongol hanya tisu yang ia bawa agak banyak pada video tgl 6 November 2015 untuk berinteraksi dengan penonton. Ia memanggil 5 (lima) orang penonton pria untuk menguji 'keaslian' dari para lelaki tersebut dengan melihat ciri-ciri mereka menggunakan tisu. Selebihnya, Mongol tidak menggunakan alat bantu lain selain wireless microphone yang merupakan standar penyiaran dalam menyampaikan materinya. Untuk melancarkan komunikasi dengan penontonnya, logat yang ia gunakan saat tampil lebih banyak menggunakan logat Betawi bercampur dengan logat Manado. Sesekali ia menggunakan logat Batak saat ia menceritakan dialognya dengan orang Batak. Logat Betawi tersebut ia tambahkan istilah lain yaitu Coy, Bang, Bro atau pernah Beb. Khusus untuk $C o y$, ia seringkali menggunakan sebutan ini sebagai sapaan kepada penonton agar ia menjadi akrab, karena Coy biasanya adalah sapaan akrab kapada teman. Menurut Akhaya di IDN Times, panggilan Coy dikeluarkan saat momen maskulin terjadi. Baik itu antar cowok atau antar cewek, momen maskulin antar sahabat bisa terjadi. Sementara itu, penggunaan Coy lebih umum di antara sesama teman cowok (Akhaya, 2018). Nampaknya, Coy digunakan Mongol untuk menunjukkan sisi maskulinnya atau ingin dianggap maskulin. Namun, sapaan tersebut juga seringkali dibarengi dengan gestur gemulai yang merupakan act-out Mongol saat mempraktekkan ciri-ciri KW. Gestur gemulai ini biasanya disebut dengan ngondek. Gestur ini juga sering kali muncul walaupun ia tidak sedang membicarakan mengenai KW.

Penampilan fisik Mongol dari penelitian sebelumnya di 2013 juga tidak terlalu banyak berubah. Hanya ia nampak lebih berisi dibandingkan dengan awal kemunculannya di televisi pada tahun 2011. Ia masih setia dengan rambut cepak/tipis, dengan janggut dan kumis tipis yang dipelihara dengan rapi. Ia juga masih menaruh kaca matanya di atas kepala setelah ia menyapa penonton. Ia menggunakan kaca mata seperti biasa pada saat masuk atau naik panggung, namun segera ia letakkan di atas kepala setelah beberapa saat di atas panggung.

\section{Konsistensi}

Seperti yang sudah disebutkan sebelumnya di bagian spesialisasi, materi yang konsisten diangkat di 17-video yang dianalisis di penelitian ini antara lain: Coy, menjelekkan diri (berhidung pesek, wajah seperti copet, pencuri handphone dan lain-lain), KW atau cowo ga normal, Sob, kelakuan orang Indonesia, Manado, hantu (Setan, Kuntilanak, Pocong, Wewe Gombel), ganteng, lagu anak kecil, dikira copet, cewe, kacamata di kepala dan Batak.

Kata terbanyak yang diucapkan Mongol dari 17 video adalah Coy sebanyak 168 kali. Ia tidak mengucapkan coy hanya pada 3 video yaitu tgl 5 Oktober 2015, di Jak TV, 23 Desember 2015 di NET TV dan 25 Maret 2016 di Trans7. Ketiga video tersebut, di mana Mongol tidak menyebutkan Coy, formatnya adalah wawancara pembawa acara dengan Mongol, sehingga ia tidak perlu menyapa Coy untuk mengakrabkan diri. Jika dirata-rata, maka Mongol menyebut Coy sebanyak 12 kali/episode. Bahkan ada video Mongol yang menyebut Coy sebanyak 28 kali. Materi yang secara konsisten diangkat yaitu self-deprecating atau menghina diri sendiri atau mengejek wajahnya sendiri yang dianggap tidak ganteng bagi orang kebanyakan. Materi ini dibawakan sebanyak 
57 kali yang hampir dilakukannya di setiap penampilannya di televisi. Hanya 2 kali ia tidak menghina dirinya, karena materi yang dibawakannya lebih banyak menceritakan mengenai observasi yang sengaja atau tidak sengaja ia lakukan terhadap fenomena yang terjadi di sekelilingnya. Artinya, rata-rata 3-4 kali ia menceritakan kekurangan tubuhnya untuk setiap penampilan.

Materi lain yang tentu akan konsisten ia angkat yaitu mengenai $\mathrm{KW}$ atau cowo ga normal, sebanyak 33 kali untuk 12 video, sehingga ia mengangkat mengenai $\mathrm{KW}$ sebanyak 2-3 kali per penampilan. Karena sering menggunakan istilah $\mathrm{KW}$, ia mengambil persona dirinya sebagai pakar KW internasional. Jika mengetik kata kunci 'pakar KW' di mesin pencari seperti Google, maka berita tentang dirinyalah yang akan muncul. Dalam sebuah wawancara di merdeka.com, berikut cuplikan jawaban Mongol mengenai personanya: "Kalau stand up ada terkenal namanya persona, ciri khas seseorang. Setiap comic nggak boleh sama. Misalnya Raditya Dika soal galau, hubungan dengan pacar. Kalau Panji soal ini. Nah gue mikir, soal apa ya. Gue akhirnya dapatlah soal pakar $K W$ internasional." (Khumaini, 2015)

Materi lain yang secara konsisten diangkat dalam penampilan Mongol dari awal kemunculannya di tahun 2011 yaitu: Manado (asal daerahnya dan perilaku masyarakatnya) sebanyak 14 kali, mengenai hak istimewa orang ganteng sebanyak 12 kali, seringkali dicurigai sebagai copet atau pencuri sebanyak 9 kali, mengakui dirinya yang sudah bisa dianggap sebagai artis sebanyak 9 kali, dan sering dianggap orang Batak sebanyak 6 kali.

Materi yang sebelumnya belum pernah diangkat di penelitian tahun 2013, namun secara konsisten diangkat di 17-video yang diamati, yaitu antara lain: perilaku orang Indonesia sebanyak 30 kali, hantu sebanyak 13 kali, lagu anak kecil 11 kali, perilaku perempuan 8 kali dan alasan kaca mata berada di kepala sebanyak 7 kali. Mongol juga melontarkan pesan moral sebanyak 6 kali kepada penontonnya. Walaupun materi ini belum pernah diangkat sebelumnya, namun materi tersebut di atas diulang-ulang ceritanya di setiap penampilannya, sehingga dapat memperkuat personal branding-nya.

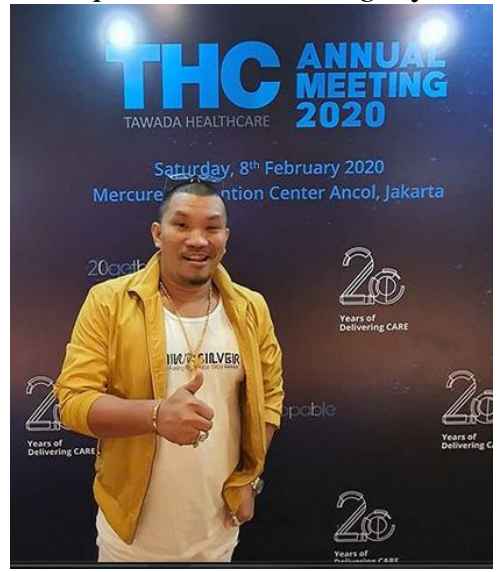

Sumber: Instagram @ mongolstres

Gambar 7. Mongol Stres

Dari konsistensi delivery atau penyampaian materi Mongol seperti yang sudah disebutkan di atas, pada bagian spesialisasi, hampir tidak ada inkonsistensi yang ia tampilkan. Ia menggunakan gaya kostum yang sama, yaitu semi-formal, namun tetap khas gaya Mongol. Ia tidak menggunakan kostum yang aneh atau berkesan ingin tampil lucu. Jika dilihat dari vlog yang dibuatnya di youtube, atau ia diundang ke vlog dari Youtuber lain, maka nampak kesehariannya tidak jauh berbeda dengan ketika ia tampil di televisi. Mongol tampil konsisten dengan kaus / t-shirt yang seringkali ketat, dipadu dengan rompi atau jaket atau blazer, celana jeans, anting berlian di telinga kiri dan kacamata. Ia seringkali menggunakan perhiasan berlebih, seperti kalung dan cincin, menurutnya agar ia tidak disangka copet (Pamungkas, 2014). Penampilan fisiknya juga konsisten rapi dengan janggut dan kumis tipis.

\section{Perbandingan dengan Penelitian Sebelumnya (2013)}

Pada penelitian sebelumnya, yang menganalisis 16 (enam belas video) Mongol stand-up comedy di Metro TV dari tahun 2011 hingga 2013, kesimpulannya adalah: Mongol memiliki personal branding yang kuat. Berdasarkan 5 (lima) kriteria personal 
branding, yaitu: spesialisasi, konsistensi, autentisitas, relevansi dan terlihat.

Dari sisi autentisitas dan keaslian dirinya, terlihat dari buku otobiografi yang ia tulis berjudul "Abdel \& Mongol: It's Real, Man!" maka nilai autentisitas dari sisi materi sebesar $85,71 \%$ dan delivery sebesar $75 \%$. Presentase yang tinggi juga terjadi pada relevansi materi (dan delivery) yang disampaikan Mongol dengan tema acara, levelnya berada di 94\%. Ia juga rajin terlihat tampil di acara Stand Up Comedy Show di Metro TV dengan kemunculan hingga 1-2 kali per bulan. Sebuah frekuensi yang tinggi untuk seorang komika (Widiyastuti, 2013).

Jika dibandingkan spesialisasi dan konsistensi personal branding Mongol pada penelitian tahun 2013 dan penelitian ini maka hampir tidak banyak perubahan yang dilakukan olehnya. Dari sisi spesialisasi materi, ia tetap mengangkat $\mathrm{KW}$, tetap menjelekkan dirinya sendiri, perilaku orang Manado, membicarakan orang ganteng kemudian membandingkan dengan dirinya, seringkali dikira copet karena wajah seramnya, ingin dianggap sebagai artis dan wajahnya yang sering dikira orang Batak. Ia hanya menambahkan materi baru berdasarkan observasinya yaitu seputar perilaku aneh dan lucu orang Indonesia, cara mengusir hantu, mempertanyakan logika di lirik lagu anak kecil dan alasan kenapa selalu meletakkan kaca mata di kepala. Untuk itulah, ia masih masuk ke dalam komika observasionalis atau pengamat, yaitu seseorang yang memberi komentar atau penilaian berdasarkan apa yang telah mereka amati selama ini (Shore, 2004) karena ia menceritakan kembali pengamatan sehari-harinya, lalu didramatisasi agar menjadi lucu. Ia juga masih konsisten sebagai storyteller atau pendongeng, yaitu membagi pengalaman dan konsentrasi pada hal yang lebih tahan lama seperti keluarga, bisnis, atau situasi sosial (Helitzer \& Shatz, 2005). Ia cenderung menghindari berita terhangat ataupun hal-hal lain yang sensitif seperti politik, SARA dan pornografi, karena tujuan ia berkomedi adalah menghibur dan tidak ada idealisme tertertu agar ia dapat diterima di banyak segmen (Widiyastuti, 2013).

\section{PENUTUP}

Seorang komika stand-up comedy tidak cukup hanya persona atau ciri khasnya pada saat naik panggun, tetapi juga diperlukan personal branding yang kriterianya adalah: spesialisasi, konsistensi, autentisitas, relevansi dan terlihat. Persona dalam stand-up comedy dapat diklasifikasikan sebagai spesialisasi, dari sisi materi maupun delivery. Persona yang sudah direncanakan sebelumnya tersebut harus dikomunikasikan secara terus-menerus untuk menjaga konsistensinya. Apabila ada hal lain yang ingin dikomunikasikan secara terusmenerus namun di luar dari persona yang direncanakan, maka masih bisa dilakukan asalkan tidak bertentangan dengan persona awalnya, apalagi sampai berubah, karena dapat membuat bingung penontonnya. Untuk memudahkan menjaga konsistensi, maka seorang komika sebaiknya autentik dalam berkomunikasi, atau mengambil persona yang berkaitan dengan dirinya dan tidak dibuatbuat. Hal inilah yang disebut autentisitas, dan Mongol autentik sebagai pakar KW, sesuai dengan personanya. Ia tidak mengatakan bahwa ia sendiri adalah $\mathrm{KW}$, namun ia menceritakan pengamatannya pada perilaku laki-laki yang kurang maskulin, sehingga ia cocok disebut pakar KW.

Relevansi antara persona atau spesialisasi dengan tema yang diminta oleh penyelenggara acara stand-up comedy sangatlah penting. Stand-up comedy adalah salah satu genre komedi di Indonesia yang dianggap sebagai komedi yang pintar, dan komika yang pintar adalah yang mampu merelevansikan topik dengan personanya sendiri. Terakhir, seorang komika sebaiknya selalu terlihat di berbagai media. Apabila ia sudah tidak diundang ke acara stand-up comedy di televisi, maka ia dapat memanfaatkan media sosial seperti Instagram atau Youtube dengan membuat konten yang konsisten dengan branding-nya, agar ia tetap terlihat memenuhi 4 (empat) kriteria personal branding sebelumnya, agar personal branding-nya konstan atau bahkan semakin kuat. 


\section{REFERENSI}

Akhaya, P. (2018, Mei 10). IDN Times - Life. Retrieved from IDN Times: https://www.idntimes.com/life/relatio nship/prisca/arti-panggilan-sayang-keteman $/ 3$

Boles, J. (2010). Life upon wicked stage: A sociologist's look at people in show business. iUniverse.

Charney, M. (2005). Comedy: A geographical and historical guide. Praeger Publisher.

Connor, S. (2004). The Cambridge Companion to Postmodernism. Cambridge University Press.

Drewniany, B. L., \& Jewler, A. J. (2008). Creative Strategy in Advertising (9 ed.). Thomson Wadsworth.

Fadeli, M. (2014). Personal Branding Pada Industri Citra. J-IKA / Jurnal Ilmu Komunikasi, 3.

Eriyanto. (2008). Analisis Framing: Konstruksi, Ideologi dan Politik Media. Yogyakarta: LKiS.

Gad, T., \& Rosencreutz, A. (2002). Managing Brand Me: How tho Build Your Personal Brand. Pearson Education Limited.

Helitzer, M., \& Shatz, M. (2005). Comedy Writing Secrets: The Best-Selling Book on How to Thinck Funny, Write Funny, Act Funny, and Get Paid It (2 ed.). Writers Digest Books.

Jaka Atmaja, C. N. (2019). Hubungan Daya Tarik Dan Pola Menonton Pada Program Stand-Up Comedy Indosiar Terhadap Kepuasan Menonton. J-IKA / Jurnal Ilmu Komunikasi, 51.

Keller, K. L. (2008). Strategic Brand Management: Building, Measuring and Managing Brand Equity (3 ed.). Pearson Education, Inc.

Khumaini, A. (2015, Oktober 25). Merdeka Khas. Retrieved from Merdeka.com: https://www.merdeka.com/khas/nggak -gampang-jadi-orang-ngondekwawancara-mongol-stres.html

Kurniawan, I (2012).Mongol Pernah Hidup Lontang Lantung dan Tidur di Emperan Toko. (2012, Februari 11).
Retrieved Juni 3, 2013, from Tabloidbintang.com:

http://www.tabloidbintang.com/berita/ sosok/20809-mongol-pernah-hidup-

lontang-lantung-dan-tidur-diemperan-toko.html

Montoya, P., \& Vandehey, T. (2002). The Personal Branding Phenomenon: realize greater influence, explosive income growth and rapid career advancement by applying the branding techniques of Michael, Martha \& Oprah. Personal Branding Press Publishing.

Montoya, P., \& Vandehey, T. (2009). The Brand Called You: Create a Personal Brand That Wins Attention and Browse Your Business. McGraw-Hill Companies, Inc.

Neal, B. (2008). How to Get Started \& Manage Your Stand-Up Comedy Career: Inside the Serious Business of Comedy. Magic Lamp Press.

Pamungkas, Y. A. (2014, Februari 8). Tabloid Bintang - Berita. Retrieved from TabloidBintang.com:

https://www.tabloidbintang.com/berit a/polah/read/3226/Bawakan-Standup-Comedy-Sekali-Tampil-MongolDibayar-Rp-225-Juta-per-15-Menit

Papana, R. (2012). Kiat Tahap Awal Belajar Stand Up Comedy Indonesia: Kitab Suci. Media Kita.

Rampersad, H. K. (2009). Authentic Personal Branding: A New Blueprint for Building and Aligning a Powerful Leadership Brand . Information Age Publishing, Inc.

Sastra, I. (2015, November 17). Blogspot. Retrieved from IwelSastra.com: http://iwelsastra.blogspot.com/2015/1 1/stand-up-everywhere-rcti.html

Shore, S. C. (2004). Sandi C. Shore's Secret to StandUp Success: a Complete StepBy-Step Workbook. Emmis Books.

Widiyastuti, N. (2013). Analisis Personal Branding Komika Stand Up Comedy Show di Metro TV - Penelitian MixedMethods pada Komika Mongol). Jakarta: STIKOM Interstudi. 
-, Stand Up Komedi yang Paling Populer. (2012). Retrieved Mei 2013, 2013, from Lihat.co.id: http://www.lihat.co.id/2013/01/7stand-up-komedi-yang-palingpopuler.html

-. Mongol dari Stand Up Comedy Bisa Beli Rumah. (2012, Juni 10). Retrieved Juni 3, 2013, from Poskotanews.com: http://www.poskotanews.com/2012/0 6/10/mongol-dari-stand-up-comedybisa-beli-rumah

\section{BIODATA PENULIS}

Novrita Widiyastuti, S.Sos, M.Si., lahir di Jakarta, 1 November 1979. Meraih gelar Sarjana Komunikasi bidang Komunikasi-
Periklanan dari Universitas Indonesia, serta lulus cum laude S-2 jurusan Entertainment Communication dari STIKOM InterStudi pada 2013. Ia kini adalah dosen di LSPR Communication and Business Institute (2006sekarang), pernah mendapat penghargaan The Best Expertise Lecturer (2011) dan Runner-up Expertise Lecturer (2016). Ia juga konsultan humor di IHIK3 untuk menjalankan misi lembaga ini menjadi sebuah wadah yang dapat menjembatani antara pelaku dan penikmat humor. Tujuannya adalah agar para pelaku dan penikmat dapat menikmati humor dengan cara cerdas dan benar. Humor bukan sekadar bercanda, tetapi juga memiliki teori dan cara tersendiri supaya dapat mencapai tujuan yang diinginkan. 